\title{
$\mathrm{M} \& S$ 기법을 통한 다기능 레이다의 4면 동시 운용을 위한 자원관리 개발
}

\section{Development of Resource Management for Simultaneous Four-Face Operation of Multi-Function Radar Using Modeling and Simulations}

\author{
박명훈 · 권세웅·김현승 · 전우중 \\ Myung-Hoon Park $\cdot$ Se-Woong Kwon $\cdot$ Hyun-Seung Kim $\cdot$ Woo-Joong Jeon
}

요 약

일반적으로 1 면의 안테나로 탐색하는 탐색레이다와 다르게 다기능 레이다는 4 면이 고정되어 운용한다. 다기능 레이다 의 4면은 운용이 독립적이고 위상배열 안테나를 사용하여 빔을 동시에 운용할 수 있는 장점을 가진다. 반면, 면이 가까이 붙어 있어 빔을 방사할 때 다른 면에 간섭이 발생되는 문제점이 있다. 탐색의 경우 같은 시점에 같은 파형을 방사하기 때문에 간섭을 피할 수 있지만, 추적은 각 표적마다 빔 송신 시점과 사용하는 파형이 달라 간섭이 발생한다. 본 논문에서 는 이러한 문제점을 해결하기 위해 4면 추적 동시 운용을 위한 추적 동기화 개념을 적용한 자원관리 모델을 개발하였다. 개발한 자원관리 모델을 Modeling and Simulation $(\mathrm{M} \& S$ ) 도구를 통해 표적 1,000 대 시나리오에 따른 자원 관리의 변화를 지표로 분석하였다. 그 결과, 새로운 자원관리 모델을 통해 시간 자원을 더 효율적으로 사용하여 레이다 성능이 향상된 것을 보였다.

\begin{abstract}
In search radar systems, one face of the antenna generally rotates. By contrast, multi-function radar systems operate with four faces in a fixed position. Four-face multi-function radar is operated independently and has the advantage of being able to operate a beam simultaneously using a phased array antenna. However, there are disadvantages in terms of interference between the faces during beam transmission. A search beam can avoid such interference by concurrently sending another beam that is not for tracking owing to differences in their waveforms and transmission times according to the target location and type. In this study, to overcome such disadvantages, we developed a resource management model that applies the concept of tracking synchronization for a simultaneous four-face operation. We analyzed the results of resource changes in the target \#1,000 scenario using a resource management model we developed through a modeling and simulation (M\&S) tool. As a result, the new resource management system operates the time resources efficiently and improves the radar performance.
\end{abstract}

Key words: Multi Function Radar, Resource Management, Four-Face Simultaneous Operation, Modeling and Simulation, MFR Simulation.

(주) LIG 넥스원(LIG Nex1 Co., Ltd.)

- Manuscript received July 29, 2020 ; Revised August 24, 2020 ; Accepted October 22, 2020. (ID No. 20200729-063)

- Corresponding Author: Myung-Hoon Park (e-mail: myunghoon.park2@lignex1.com) 


\section{I. 서 론}

최근 레이다의 목적과 역할이 다양해지면서 하나의 레 이다로 다양한 기능 및 성능이 요구된다. 이에 따라 위상 배열 안테나를 사용한 다기능 레이다의 발전이 급속히 진행되고 있다 ${ }^{[1]}$. 다기능 레이다는 4 면으로 고정되어 전 방위를 탐지 및 추적한다. 다기능 레이다의 탐색은 각 면 이 정해진 빔 스케쥴링에 따라 동일한 파형으로 동시에 방사한다. 전 방위에 분포된 표적이 탐색 빔에 의해 탐지 되면 추적 자원을 할당해 추적 빔을 방사하여 추적하게 된다. 추적 빔은 표적의 위치, 기동 등 표적 특성에 따라 서로 다른 파형을 사용한다. 4 면으로 구성된 다기능 레이 다는 면 간 거리가 가까워 상호 전파 간섭에 대한 고려가 필요하다. 탐색은 동일한 시간에 같은 파형을 방사하여 면 간 전파간섭이 발생하지 않지만 추적의 경우, 서로 다 른 파형을 사용하기 때문에 간섭이 발생하여 추적 성능 을 저하시킨다. 이를 피하기 위해 기본적으로 한 면 또는 SPY-1D 레이다와 같이 대칭 2면 끼리 빔을 운용한다. 하 지만 4면을 동시에 운용하지 않는다는 것은 레이다 자원 중 하나인 시간자원에 대한 손실이 발생하여 레이다 성 능이 저하되는 것을 뜻한다. 이를 보완하기 위해 본 논문 에서는 각 면의 추적을 동기화하는 알고리즘을 적용한 자원관리 모델을 개발하여 시간자원을 좀 더 효율적으로 사용하였다.

다기능 레이다는 탐색과 추적을 동시에 운용하기 때문 에 자원관리 방법에 따라 레이다의 성능이 다양하게 변 하기 때문에 이에 관한 연구가 많이 진행되어 왔다 ${ }^{[2] ~[4]}$. 본 논문에서는 자원관리에 따른 레이다 성능 차이를 분 석하기 위해 기존 개발된 함정용 다기능레이다 $\mathrm{M} \& S$ 도 구 활용하였다 ${ }^{[5]}[7]$. 기존 도구에 사용된 기 개발된 자원 관리 모델에 추적 동기화 알고리즘과 4면 동시 운용 개념 을 적용하여 표적 1,000 대에 대한 탐지 및 추적 자원관리 를 분석하였다. 이를 위해 2장에서는 개발된 자원관리 모 델을 설명하였고, 3 장에서는 $\mathrm{M} \& \mathrm{~S}$ 도구를 통해 개발된 자 원관리에 따른 자원관리를 탐지시간(frame time)을 기준 으로 분석하였다. 이때 탐지시간이란 탐색 빔이 한 면에 할당된 영역 전체를 탐색하는데 걸리는 시간을 의미한다.

\section{II. 설계 내용}

본 논문에서 모의한 다기능 레이다는 탐색을 기본으로 표적 특성에 따라 서로 다른 추적 성능을 사용한다. 추적 개념에는 스캔 중 추적(track while scan: TWS) 및 빔을 할 당하여 추적하는 개념이 있다. TWS는 탐지 정보를 이용 한 추적으로 따로 빔이 할당되지 않기 때문에 탐색 자원 에 의존한다. 반면 추적 빔을 할당하여 추적하는 경우, 추 적 파형 및 갱신률에 따라 할당되는 추적자원이 달라진 다. 개발한 자원관리 모델은 탐색 중 탐지된 표적 정보에 따라 표적 종류 및 위치를 바탕으로 추적 빔을 할당하여 설정된 시간에 빔을 방사하도록 제어하는 역할을 한다.

\section{2-1 자원관리 모델}

기존 자원관리 모델은 최대 탐지 거리를 기준으로 추 적 빔 성능을 고정하여 사용하였고, 추적 시 한 면씩 순차 적으로 레이다 면을 운용하였다[7]. 최대 탐지 거리를 기 준으로 설계된 추적 빔은 근거리 표적의 경우, 높은 신호 대 잡음비를 가져 에너지 측면에서는 이점을 가진다. 하 지만 그만큼 긴 펄스 반복 주기(pulse repetition interval: $\mathrm{PRI}$ 를 가져가야하기 때문에 시간 측면에서는 비효율적 인 운용이 될 수 있다. 또한 한 면 순차 운용을 하게 되면 임의의 한 면을 운용할 때 다른 면을 운용할 수 없어 다 수의 표적을 추적할 시에는 시간 자원 소모량이 커지게 된다. 이러한 기존 자원관리의 단점을 해소하기 위해 그 림 1 과 같이 추적 빔 파형 변화 및 4 면 방사 시간 동기화 의 개념을 추가한 새로운 자원관리를 개발하였다 ${ }^{[8],[9]}$.

에너지 측면에서 설계치 중 duty cycle이 정해진 상황 에서 PRI를 줄이면 신호 대 잡음비가 줄지만 시간 자원을 아낄 수 있다. 기존 자원관리 모델은 근거리에서 신호 대 잡음비가 상대적으로 높기 때문에 PRI를 줄일 수 있는 점 을 이용해 그림 2와 같이 표적 거리에 따라 서로 다른 추 적 파형을 사용하였다.

식 (1)을 통해 레이다에 요구되는 탐지확률 $(P d)$ 및 오 탐지율 $\left(P_{f a}\right)$ 을 만족하는 신호 대 잡음비를 기준으로 표적 거리별 서로 다른 PRI로 설정할 수 있으며, 그 결과는 그 림 3 과 같다. 이때 $R$ 은 추적하는 표적의 거리이며, 레이 다 운용에 따라 거리 간격은 변경할 수 있다. 이를 통해 


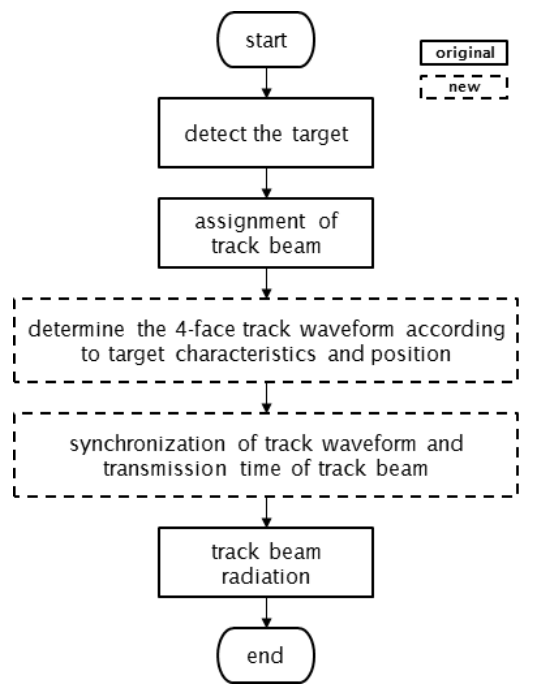

그림 1. 자원관리 순서도

Fig. 1. The flowchart of resource management.

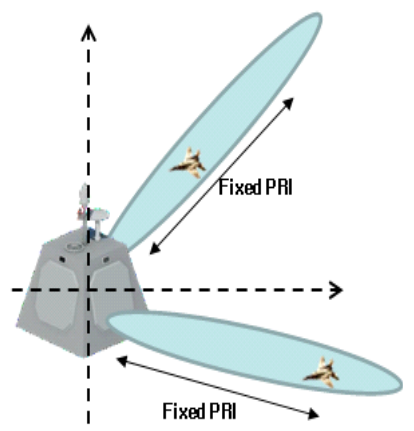

(a) 송신

(a) Transmission

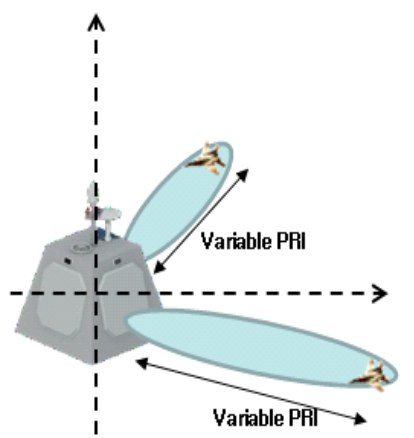

(b) 수신

(b) Reception

그림 2. 추적 파형 가변 알고리즘 개념

Fig. 2. The concept of variable track waveform algorithm.

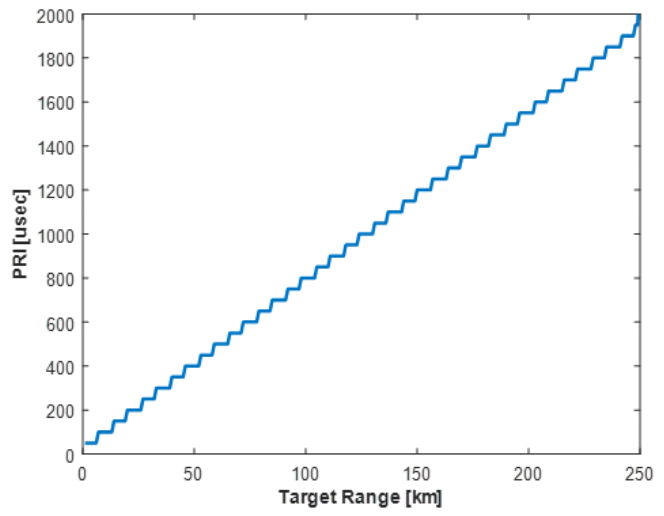

그림 3. 표적 거리에 따른 파형 결과

Fig. 3. The result of waveform according to range of target.

전 구간에서 신호 대 잡음비를 만족하면서 동시에 추적 자원 소모량을 줄여 좀 더 효율적으로 레이다를 운용할 수 있다.

$$
\operatorname{PRI}(R)=\left\lceil\frac{\frac{R}{0.15} \times 1.15}{50}\right\rceil \times 50 \quad[u s]
$$

추적 PRI를 거리에 따라 줄여 시간자원을 감소했지만, 서로 다른 파형을 사용하기 때문에 그림 4와 같은 서로 다른 면의 간섭을 피할 수 없다. 현재 일반 대공 표적에 대해서는 LPRF 파형을 사용하고, 저고도 근접 표적의 경 우, 클러터 제거를 위해 MPRF 파형을 사용한다. 만일 대 공 표적에 대해 레이다 1 면에서 방사한 송신 에너지가 2 면의 수신구간에 수신되면 추적 성능을 저하시킬 뿐만 아니라, 하드웨어 적으로 부담을 줄 수 있다. 또한 3 면에 서 MPRF를 사용하면 다른 면에 연속적으로 큰 에너지가

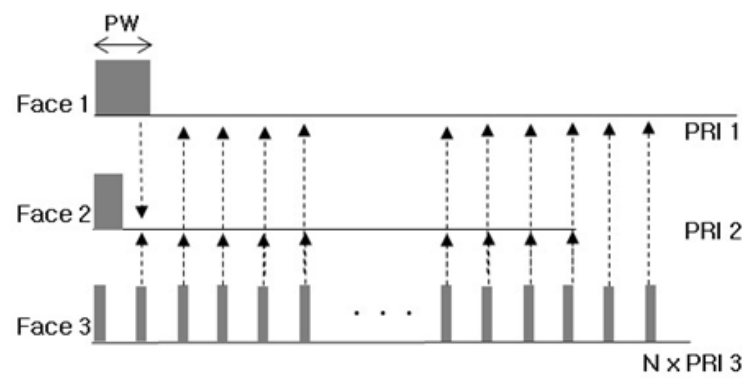

그림 4. 면 상호간 간섭 개념

Fig. 4. The concept of face interference. 
수신되어 추적이 불가능한 상태가 된다. 나아가면 간 거 리가 가까워 표적의 반사 신호가 다른 면으로 수신되는 경우도 발생할 수 있다. 이러한 면 간 간섭을 피하면서 4 면을 동시에 운용하기 위해 추적 거리별로 구분한 PRI를 기준으로 추적 빔의 송신 시간을 동기화하였다. 또한 면 간 간섭을 줄이기 위해 운용되는 주파수를 이격시켜 사 용함으로써 표적의 반사 신호가 다른 면에 수신되는 경 우를 피하였다 ${ }^{[10]}$.

자원관리 모델은 그림 5 와 같이 임의의 면에서 추적 빔 을 방사할 때 다른 면의 추적 후보 중 같은 파형이 있는 지 판단하여 동시에 방사하도록 시간을 동기화한다. 다른 면, 같은 파형의 추적 빔을 동시에 방사하면 1 면 순차운 용보다 최대 3 배에 해당되는 시간 자원을 추가 확보할 수

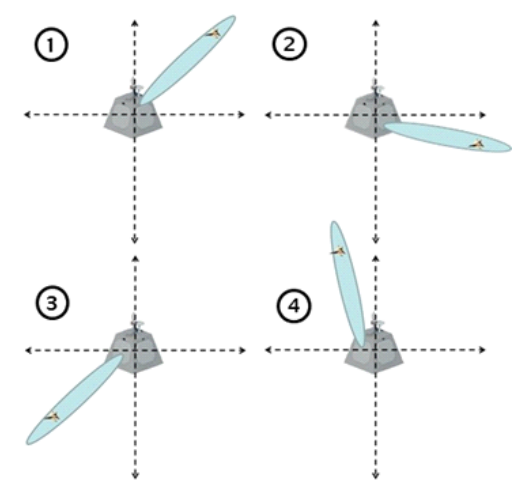

(a) 1 면 순차 운용

(a) Operation of 1-face one by one

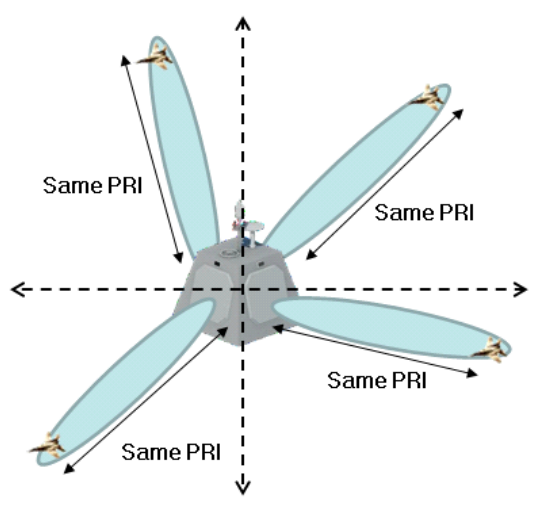

(b) 4 면 동시 운용

(b) Simultaneous operation of 4-face

그림 5. 안테나 면 운용 개념

Fig. 5. The concept of operation of radar face.
있게 된다. 자원관리 모델을 변경하면서 최종적으로 설계 된 다기능레이다는 하나의 dwell동안 목적에 따라 근거리 및 장거리, 저고도 및 고고도를 나눠 서로 다른 파형과 빔 패턴을 사용하여 탐색 빔을 운용한다. 4면이 동시에 정해 진 빔 스케쥴링에 따라 탐색 빔을 방사하다가 표적을 탐 지하면 표적 정보를 이용해 서로 다른 추적 파형을 할당 한다. 자원관리 모델은 정해진 자원 중 4 면으로부터 받은 서로 다른 표적의 추적 정보를 이용하여 파형 및 방사 시 간 등을 설정하여 빔을 할당한다. 한 면이 추적 빔을 방사 할 때 다른 면에서 같은 파형을 사용하는 추적 빔이 없을 경우, 전파 간섭 방지를 위해 다른 면은 아무 동작을 하지 않도록 제어하고, 같은 파형의 추적 후보가 존재하면 동 시에 방사하여 전파 간섭 없이 시간 자원을 줄이는 역할 을 수행한다. 이러한 동작을 시간 축에서 나타내면 그림 6과 같다.

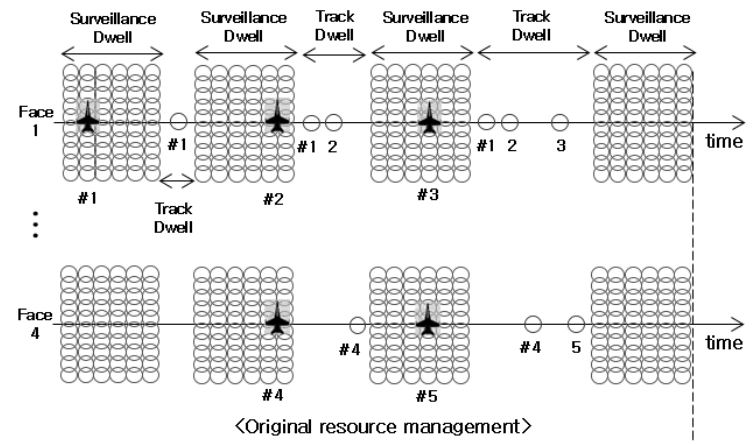

(a)

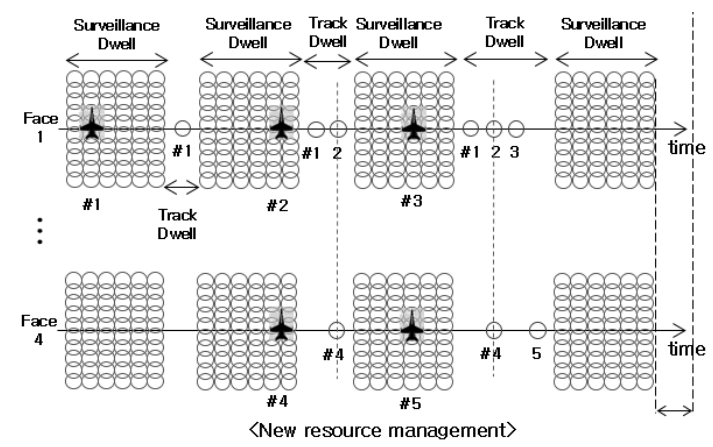

(b)

그림 6. 레이다 면 운용에 따른 빔 스케쥴링

Fig. 6. The beam scheduling according to operation of radar face. 
파형 및 방사 시간 동기화를 맞추지 않으면 그림 6(a) 와 같이 잡힌 순서대로 추적 빔을 방사한다. 반면 동기화 를 맞추게 되면 그림 6(b)와 같이 두 번째 탐색 dwell의 첫 번째 면에서 2번 표적, 네 번째 면에서 4번 표적이 탐지됐 을 때 서로 같은 PRI로 동시에 추적 빔을 방사하게 된다. 만일 다른 면에서 같은 PRI를 가지는 표적이더라도 다른 탐색 dwell에 잡히면 추적 빔의 방사 시간이 서로 다르다. 이는 몇 개의 탐색 dewll에 해당되는 추적 시간들을 동기 화함으로써 시간 자원을 줄일 수 있다. 자원관리 모델의 동기화 과정은 탐색 dewll이 끝나는 시점에 이뤄지며, 표 적이 많을수록 시간 자원 소모의 감소량은 증가한다.

\section{III. 시뮬레이션 결과}

\section{3-1 시뮬레이션 조건}

본 논문에는 새로운 자원관리 모델을 반영한 시뮬레이 션 도구를 이용하여 표적 1,000 대에 대한 다기능레이다의 동시 탐지 및 추적 성능을 기존 자원관리 모델과 비교하 여 분석하였다. 기존 자원관리 모델은 최대 탐지거리를 기준으로 설계된 파형으로 고정되어 있으며, 면 간 전파 간섭을 피하기 위해 1 면씩 순차적으로 운용한다. 이에 대 해 기존 연구에서 표적 수에 따른 추적 자원의 결과 표적 540 대에서 동시 탐지 및 추적이 불가능한 것을 보았다[7]. 따라서 표적 1,000 대에 따른 결과 비교를 위해 기존 자원 관리 모델에서 추적 파형 가변 알고리즘만 반영하였다. 그에 따른 결과는 시나리오1 분석을 통해 표적 1,000 대 추적이 가능한 것을 볼 수 있다. 두 자원관리 모델의 성능 을 비교하기 위해 표 1 의 시나리오1과 같이 설정하였다.

표 1. M\&S분석 시나리오 요약

Table 1. Summary of M\&S analysis scenario.

\begin{tabular}{|c|c|c|c|c|c|}
\hline Scenario & \multicolumn{4}{|c|}{ Maneuvering } \\
\hline 1 & \multicolumn{4}{|c|}{ Ship (\#200): Get away form radar } \\
Type & $\begin{array}{c}\text { Number } \\
\text { of } \\
\text { target }\end{array}$ & $\begin{array}{c}\text { Range } \\
(\mathrm{km})\end{array}$ & $\begin{array}{c}\text { Azimuth } \\
(\mathrm{deg})\end{array}$ & $\begin{array}{c}\text { Altitude } \\
(\mathrm{km})\end{array}$ & $\begin{array}{c}\text { Track } \\
\text { period } \\
(\mathrm{Hz})\end{array}$ \\
\hline Ship & 200 & $5: 5: 10$ & $0: 3: 360$ & 0.02 & 1 \\
\hline Aircraft & 800 & $10: 5: 65$ & $0: 5: 360$ & $5: 1: 11$ & 1 \\
\hline
\end{tabular}

두 자원관리 모델의 차이와 한계점을 보기 위해 대함 200 대, 대공 800 대가 다기능레이다를 기준으로 근거리에서 부터 최대 거리까지 퇴각 기동하여 자원관리 변화를 비 교 분석하였다.

\section{3-2 기존 vs 새로운 자원관리 결과 비교}

시나리오 1을 통해 기존 자원관리와 새롭게 개발한 자 원관리에 대한 비교를 진행한 결과, 그림 7 및 그림 8과 같다. 그림 7은 최대 표적 거리에 따른 전체 탐지시간의 결과이고, 그림 8 은 그에 따른 각 빔의 자원 할당량 변화 이다. 기존 자원관리의 경우, 표적 1,000 대에 대한 동시 탐지 및 추적 가능 거리가 약 $170 \mathrm{~km}$ 로 이때 최대 탐지시 간은 45 초이다. 이는 새로운 표적에 대해 45 초 후에 탐지 가 되면 대함유도탄과 같은 위험이 높은 표적에 대해 자 함 방어 능력이 현저히 저하되는 것을 뜻한다. 또한 표적 이 $170 \mathrm{~km}$ 이상 더 멀어지면 추적 자원이 $100 \%$ 할당되 어 더 이상 탐색 빔을 방사할 수 없어 기본적인 탐색의 임무가 제한된다. 반면, 새롭게 개발한 자원관리는 170 $\mathrm{km}$ 에서 1,000 대의 표적을 동시에 탐지 및 추적이 가능하 며, 이때 최대 탐지시간은 약 3.3 초이다. 추적 자원할당량 은 약 $40 \%$ 로 남은 $60 \%$ 의 여유자원을 통해 추적 자원에 추가로 할당하여 $170 \mathrm{~km}$ 이상 동시 탐지 및 추적이 가능 한 것을 볼 수 있다. 시나리오 1 을 통해 표적 1,000 대의

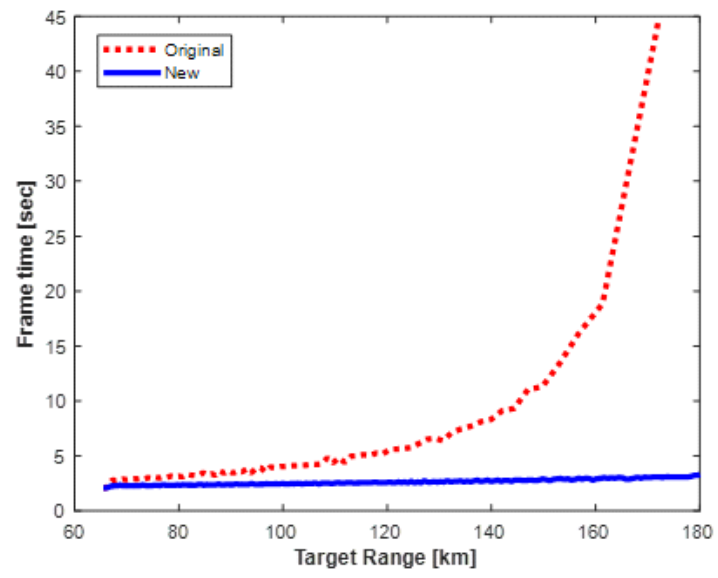

그림 7. 자원관리 모델에 따른 탐지시간 결과

Fig. 7. Result of frame time according to resource management. 


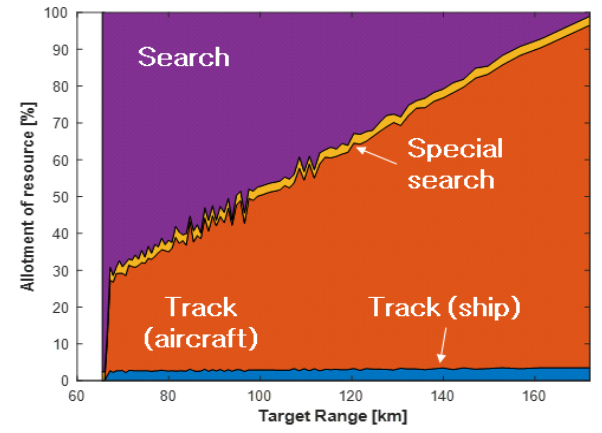

(a) 1 면 순차 운용

(a) Operation of 1-face one by one

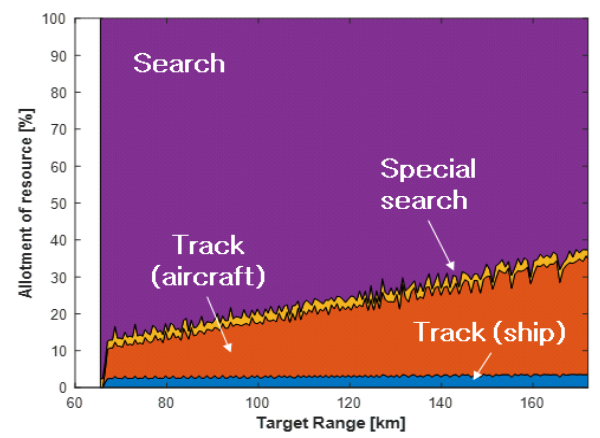

(b) 4 면 동시 운용

(b) Simultaneous operation of 4-face

그림 8. 레이다 면 운용에 따른 자원관리 결과

Fig. 8. Result of resource allotment each beam according to operation of radar face.

동시 탐지 및 추적 환경에서 기존 자원관리 모델보다 개 발한 자원관리 모델이 시간 자원 활용 측면에서의 효율 성을 검증하였다.

\section{3-3 추가 시나리오 분석 결과}

새로 개발한 자원관리 모델의 성능을 추가 검증하기 위해 표 2의 시나리오 2,3 과 같이 다양한 표적 상태에 따 른 자원관리 결과를 분석하였다. 시나리오 2 는 교전 상황 을 가정으로 대공 표적을 원거리와 근거리에 대칭으로 배치하였으며, 시나리오3은 자원관리의 최대 한계치를 볼 수 있도록 모든 대공 표적이 최대 탐지 거리에서 접근 해 오는 시나리오로 선정하였다.

그 결과, 그림 9와 같이 시나리오 2는 약 최대 탐지시 간이 3.6초 이하로 원거리부터 근거리까지 표적 1,000 대
표 2. $\mathrm{M} \& \mathrm{~S}$ 분석 시나리오 요약

Table 2. Summary of M\&S analysis scenario.

\begin{tabular}{|c|c|c|c|c|c|}
\hline Scenario & \multicolumn{5}{|c|}{ Maneuvering } \\
\hline 2 & \multicolumn{4}{|c|}{$\begin{array}{c}\text { Ship (\#200): Get away form radar } \\
\text { Aircraft (\#400): Get away form radar } \\
\text { Aircraft (\#400): Come to radar from max range }\end{array}$} \\
\hline \multirow{2}{*}{ Type } & $\begin{array}{c}\text { Number of } \\
\text { target }\end{array}$ & $\begin{array}{c}\text { Range } \\
(\mathrm{km})\end{array}$ & $\begin{array}{c}\text { Azimuth } \\
(\mathrm{deg})\end{array}$ & $\begin{array}{c}\text { Altitude } \\
(\mathrm{km})\end{array}$ & $\begin{array}{c}\text { Track } \\
\text { period } \\
(\mathrm{Hz})\end{array}$ \\
\hline Ship & 200 & $5: 5: 10$ & $0: 3: 360$ & 0.02 & 1 \\
\hline \multirow{2}{*}{ Aircraft } & 400 & 10 & $0: 4: 360$ & $2: 0.5: 11$ & 1 \\
\cline { 2 - 6 } & 400 & Max.000 & $0: 4: 360$ & $2: 0.5: 11$ & 1 \\
\hline Scenario & \multicolumn{5}{|c|}{ Maneuvering } \\
\hline 3 & Aircraft (\#800): Come to radar from far range \\
\hline \multirow{2}{*}{ Type } & $\begin{array}{c}\text { Number of } \\
\text { target }\end{array}$ & $\begin{array}{c}\text { Range } \\
(\mathrm{km})\end{array}$ & $\begin{array}{c}\text { Azimuth } \\
(\text { deg) }\end{array}$ & $\begin{array}{c}\text { Altitude } \\
\text { (km) }\end{array}$ & $\begin{array}{c}\text { Track } \\
\text { period } \\
\text { (Hz) }\end{array}$ \\
\hline Ship & 200 & $5: 5: 10$ & $0: 3: 360$ & 0.02 & 1 \\
\hline Aircraft & 800 & Max.000 & $0: 4: 360$ & $2: 0.5: 11$ & 1 \\
\hline
\end{tabular}

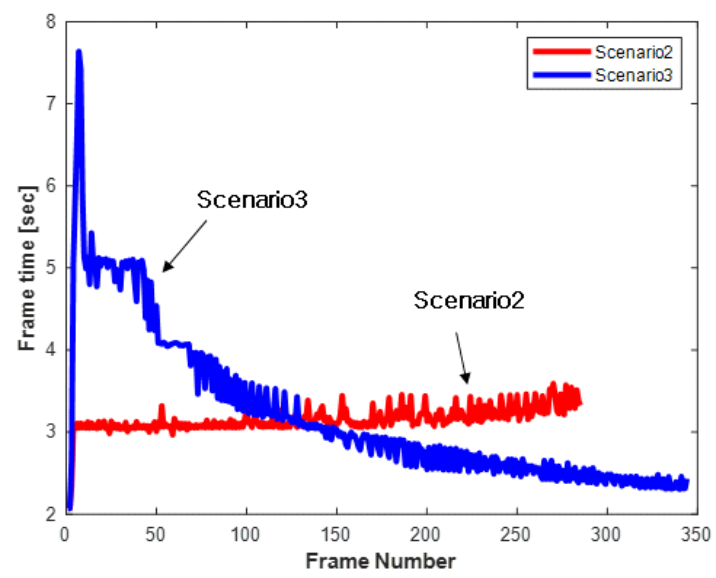

그림 9. 자원관리 모델에 따른 탐지시간 결과

Fig. 9. Result of frame time according to resource management.

에 대해 동시 탐지 및 추적이 가능하였다. 시나리오 3 은 대공 표적 800 대가 최대 탐지 거리에서 동시에 잡혀 탐지 시간이 약 7.7 초 소모되다가 추적 빔 파형 및 방사 시간의 동기화에 따라 점차 감소하는 형태를 보였다. 자원관리 결과 측면에서는 그림 10 과 같이 두 시나리오 모두 탐색 빔에 대한 자원할당량이 존재하기 때문에 새로운 표적에 대한 탐지가 가능하다. 또한 추적 할당량이 각각 최대 53 


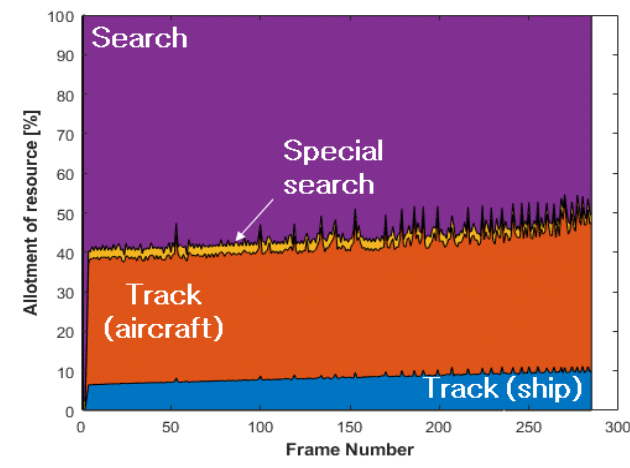

(a) 시나리오 2

(a) Scenario \#2

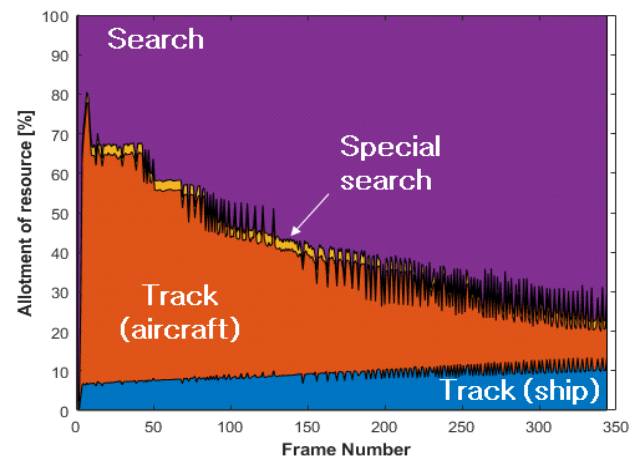

(b) 시나리오 3

(b) Scenario \#3

그림 10. 시나리오별 자원관리 결과

Fig. 10. Result of resource allotment each beam according to scenario.

$\%$ 및 $78 \%$ 로 추적 빔에 대한 여유 자원이 존재한다. 남은 자원을 이용하여 레이다 성능 향상을 위해 추적 파형 변 경이 가능한 것을 볼 수 있다.

본 논문에서는 다기능레이다의 성능 향상을 위해 효율 적인 시간 자원을 관리하도록 새로운 자원관리 모델을 개발하였다. 시간 자원 소모를 줄이기 위해 추적 파형을 표적 거리에 따라 가변으로 설정하고, 4면 동시에 빔을 방사할 수 있도록 파형 및 시간을 동기화하였다. 그 결과, 그림 11 과 같이 3 가지 시나리오 분석을 통해 개발한 자원 관리 모델의 효율적인 자원관리에 따라 레이다 성능이 향상된 것을 보았다. 이 결과를 통해 새로운 자원관리 모 델을 사용하게 되면 일반 표적 1,000 대를 동시에 탐지 및 추적하면서 추가로 탄도탄 및 대함유도탄과 같은 고위험

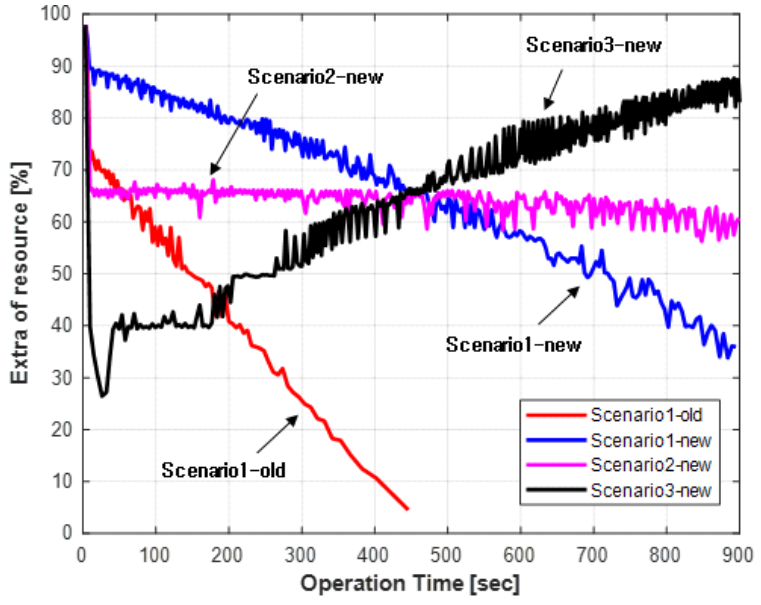

그림 11. 시나리오별 자원 여분 결과

Fig. 11. Result of extra of resource as scenario.

의 표적에 대한 대응이 가능한 것을 도출할 수 있다.

\section{$\mathrm{IV}$. 결 론}

다기능 레이다는 탐색 레이다와 다르게 빔을 자유롭게 운용할 수 있어 빔을 운용하는 자원 관리 개념이 필요하 다. 자원관리 모델은 다양한 상황에서 실시간으로 평가하 여 빔을 운용하여 레이다 성능을 유지 및 향상시키는 역 할을 한다. 이를 분석하기 위해 기존 연구에서 다기능레 이다의 성능을 예측하는 M\&S 도구를 개발하였다. 하지만 기존 $\mathrm{M \& S}$ 도구에 사용된 자원관리 모델은 면 간 전파 간 섭을 피하기 위해 1 면 순차 운용을 하며 최대 탐지 거리를 기준으로 추적 파형을 설계하여 고정으로 사용하였다. 그 결과, 표적 1,000 대 시나리오에서 큰 추적 자원의 소모량 으로 목표 거리까지 동시 탐지 및 추적이 불가능하였다.

본 논문에서는 기존 자원관리 모델의 단점을 보완하기 위해 새로운 자원관리 모델을 개발하였다. 개발한 자원관 리 모델은 표적 특성 및 거리에 따라 서로 다른 파형으로 구성하였고, 방사 파형 및 시간의 동기화를 맞춰 면 간 전 파간섭을 피하면서 4 면을 동시에 운용하여 시간 자원 소 모를 줄였다. 그 결과, 표 3 과 같이 3 개의 시나리오에 대 해 표적 1,000 대를 동시에 탐지 및 빔을 할당한 추적에 성 공한 것을 보았다.

개발한 자원관리 모델을 활용하여 향후 일반 표적 추 
표 3. $\mathrm{M} \& \mathrm{~S}$ 분석 결과 요약

Table 3. Summary of M\&S analysis result.

\begin{tabular}{|c|c|c|c|c|}
\hline Scenario & $\begin{array}{c}\text { Resource } \\
\text { management }\end{array}$ & $\begin{array}{c}\text { Max. } \\
\text { frame time } \\
(\mathrm{sec})\end{array}$ & $\begin{array}{c}\text { Avg. } \\
\text { frame time } \\
(\mathrm{sec})\end{array}$ & $\begin{array}{c}\text { Max. } \\
\text { allotment of } \\
\text { track resource } \\
(\%)\end{array}$ \\
\hline \multirow{2}{*}{1} & Old & 45 & 5.3 & 100 \\
\cline { 2 - 5 } & New & 3.3 & 3.09 & 40 \\
\hline 2 & New & 3.6 & 3.15 & 53 \\
\hline 3 & New & 7.7 & 3.20 & 78 \\
\hline
\end{tabular}

적 상황에서 탄도탄 및 대함유도미사일 등 고위험 표적 에 대한 탐지 및 추적 성능을 분석할 수 있다. 이를 통해 다수 및 다양한 표적에 대한 복합전술 상황에 따른 자원 관리 변화를 분석하여 다기능레이다의 성능을 사전 예측 하고 평가할 수 있다.

\section{References}

[1] M. Skolnik, "Radar in the twentieth century," IEEE Aerospace and Electronic Systems Magazine, vol. 15, no. 10, pp. 27-46, Oct. 2000.

[2] S. H. Jin, N. H. Jeong, J. H. Choi, S. H. Lee, C. H. Kim and K. T. Kim, "Radar Beam Scheduling Using Pareto Optimal Point to Optimize Dual Cost Function," in The Journal of Korean Institute of Electromagnetic Engineering and Science, vol. 30, no. 8, pp. 677-687, Aug. 2019.

[3] Ö. Çayir, "Radar resource management techniques for multi-function phased array radars," M.S. thesis, Middle East Technical University, Ankara, Turkey, 2014.

[4] P. W. Moo, Z. Ding, Adaptive Radar Resource Management, London, Academic Press, 2015.
[5] M. H. Park, H. S. Kim, W. J. Jeon, S. K. You, S. W. Kwon, and H. W. Moon, et al., "Development of modeling \& simulation tool for long range radar considering operational environment in time domain," The Journal of Korean Institute of Electromagnetic Engineering and Science, vol. 30, no. 7, pp. 591-602, Jul. 2019.

[6] M. I. Skolnik, Radar Handbook, 3rd ed. New York, NY, McGraw-Hill, 2008.

[7] M. H. Park, C. H. Kim, H. S. Kim, J. Y. Go, W. J. Jeon, and S. W. Kwon, et al., "Development of simulation tool for ship self defense scenario using naval multi function radar," The Journal of the Institute of Internet, Broadcasting and Communication, vol. 20, no. 2, pp. 87-96, Apr. 2020.

[8] B. L. Scala, M. Rezaeian, and B. Moran, "Optimal adaptive waveform selection for target tracking," in 2005 7th International Conference on Information Fusion, Philadelphia, PA, USA, Jul. 2005, p. 6.

[9] S. P. Sira, A. Papandreou-Suppappola, and D. Morrell, "Dynamic configuration of time-varying waveforms for agile sensing and tracking in clutter," IEEE Transactions on Signal Processing, vol. 55, no. 7, pp. 3207-3217, Jul. 2007.

[10] M. H. Park, S. W. Kwon, W. J. Jeon, H. S. Kim, S. $\mathrm{K}$. You, and K. W. Lee, et al., "Analysis of radar interference using a modeling and simulation method," The Journal of Korean Institute of Electromagnetic Engineering and Science, vol. 30, no. 10, pp. 829-838, Oct. 2019. 
박 명 훈 [LIG넥스원/선임연구원]

https://orcid.org/0000-0002-5217-0365

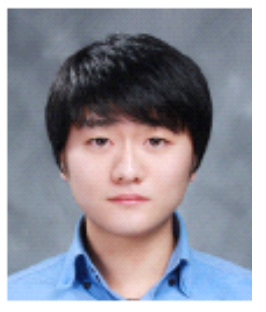

2014년 2월: 한국항공대학교 항공전자공 학과 (공학사)

2016년 2월: 한국항공대학교 항공전자정 보공학과 (공학석사)

2016년 1월 현재: LIG넥스원 SW연구소 선임연구원

[주 관심분야] 레이다 체계 설계, $\mathrm{M \& S}$, 안테나, 전파전파 등
김 현 승 [LIG넥스원/선임연구원]

https: //orcid.org/0000-0003-4021-5914

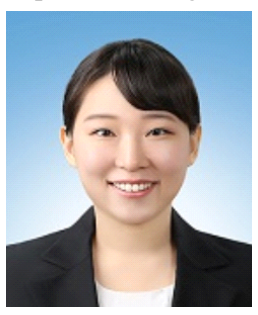

2014년 2월: 인하대학교 항공우주공학과 (공학사)

2016년 2월: 인하대학교 항공우주공학과 (공학석사)

2016년 1월 현재: LIG넥스원 SW연구소 선임연구원

[주 관심분야] 항공제어, $\mathrm{M \& S}$, 추적 알고 리즘 등
권 세 웅 [LIG넥스원/수석연구원]

https://orcid.org/0000-0002-8959-4452

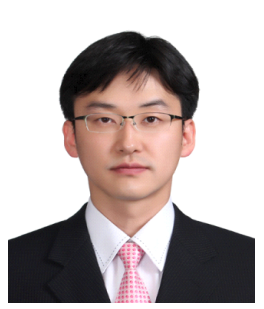

1999년 2월: 연세대학교 전파공학과 (공학 사)

2002년 2월: 연세대학교 전기컴퓨터공학 과 (공학석사)

2009년 8월: 연세대학교 전기전자공학과 (공학박사)

2009년 7월 현재: LIG넥스원 레이다연구 소 수석연구원

[주 관심분야] 능동위상배열레이다, 전파전파 등
전 우 중 [LIG넥스원/선임연구원]

https://orcid.org/0000-0003-3974-0631

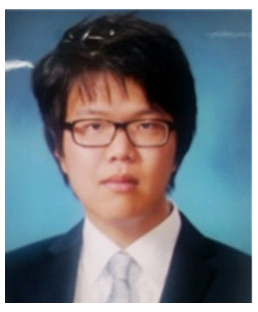

2010년 7월: 서울대학교 전기공학과 (공학 사)

2016년 2월: 서울대학교 전기공학과 (공학 석사)

2016년 1월 현재: LIG넥스원 SW연구소 선임연구원

[주 관심분야] $\mathrm{M \& S}$, 레이다, 제어 등 